\title{
Россия и северный фронт Израиля: новые грани асимметричного конфликта
}

\author{
А.А. Ермаков, А.А. Корнилов, И.В. Рыжов \\ Университет Лобачевского, \\ Россия, 603950, Нижний Новгород, пр-т Гагарина, 23 \\ E-mail: ermakov1989@mail.ru,kotva64@mail.ru,ivr@ fmo.unn.ru
}

\begin{abstract}
Аннотация. Военную операцию «Северный щит», проведенную Армией обороны Израиля на Северном фронте государства против боевиков Хезболлы в 2018-2019 гг., авторы рассматривают в контексте реализации политики безопасности государства Израиль Биньямином Нетаньяху, а также взаимодействия России и Израиля через призму фактического баланса сил на Ближнем Востоке. Прежде всего, была дана оценка важности этой военной операции в процессе разрушения туннелей «Хезболлы», созданных для блокирования поселений в Галилее, а также в контексте усиления сопротивления израильского тыла ракетным обстрелам боевиками организации. ЦАХАЛ продемонстрировал высокую боевую готовность в контексте противодействия «Хезболле», а также подготовки к намеченной военной операции, что существенно подрывает шансы радикалов повлиять на расстановку сил в регионе. Тем не менее авторы предполагают, что израильские силы ограничены в ряде ресурсов, поэтому Израиль нуждается в помощи со стороны наиболее влиятельных игроков современной международной арены, включая Россию. Что касается израильских властей, то они крайне заинтересованы в поддержке России в реализации политики безопасности, поэтому израильское направление является наиболее значимым для Российской Федерации в реализации ее ближневосточного курса. В конечном итоге авторы приходят к выводу о сотрудничестве между Израилем и Россией по двум ключевым направлениям - на уровне министерств иностранных дел обеих стран и министерств обороны, и в обоих случаях приоритетным является борьба с террористической угрозой на израильской территории.
\end{abstract}

Ключевые слова: Израиль, Россия, операция «Северный щит», Армия обороны Израиля, «Хезболла».

Благодарности: исследование выполнено при финансовой поддержке РФФИ в рамках научного проекта № 20-014-00039.

Для цитирования: Ермаков А.А., Корнилов А.А., Рыжов И.В. 2020. Россия и северный фронт Израиля: новые грани асимметричного конфликта. Via in tempore. История. Политология, 47 (4): 885-893. DOI: 10.18413/2687-0967-2020-47-4-885-893.

\section{Russia and northern battlefield of Israel: new sides of the asymmetric conflict}

\author{
Andrey A. Ermakov, Alexander A. Kornilov, Igor V. Ryzhov \\ Lobachevsky University, \\ 23 Gagarin Ave, Nizhny Novgorod, 603950, Russia \\ E-mail: ermakov1989@mail.ru,kotva64@mail.ru,ivr@fmo.unn.ru
}

\begin{abstract}
The authors consider the military operation «Northern shield» conducted by the Israel Defense Forces on the Northern front of the state against Hezbollah militants in the context of Benjamin Netanyahu's implementation of the security policy of the State of Israel, as well as interaction between Russia and Israel through the prism of the actual balance of forces in the Middle East. First of all, the importance of this military operation in the process of destruction of Hezbollah tunnels created to block
\end{abstract}


settlements in the Galilee, as well as in the context of increasing the resistance of the Israeli rear to rocket attacks by militants of the organization, was assessed. The IDF has demonstrated high combat readiness in the context of countering Hezbollah, as well as preparing for the designated military operation, which greatly undermines the chances of radicals to influence the balance of forces in the region. Nevertheless, the authors suggest that the Israeli forces are limited in a number of resources, so Israel needs help from the most influential actors of the modern international arena, including Russia. As for the Israeli authorities, they are extremely interested in Russia's support in the implementation of the security policy, therefore the Israeli direction is the most significant for the Russian Federation in the implementation of its Middle East course. Ultimately, the authors come to the conclusion about cooperation between Israel and Russia in two key areas - at the level of the foreign ministries of both countries and the ministries of defense, and in both cases the priority is the fight against the terrorist threat on Israeli territory.

Keywords: Israel, Russia, operation «Northern Shield», Israel Defense Forces, Hezbollah.

For citation: Ermakov A.A., Kornilov A.A, Ryzhov I.V. 2020. Russia and Northern battlefield of Israel: new sides of the asymmetric conflict. Via in tempore. History and political science, 47 (4): 885-893 (in Russian). DOI: 10.18413/2687-0967-2020-47-4-885-893.

Сегодня ближневосточный регион занимает важное место во внешней политике Российской Федерации, что наиболее ярко выражается в активных действиях на сирийском направлении. Наша страна выступает гарантом стабильности в международных отношениях на Ближнем Востоке, с которым её связывают многолетние экономические и политические связи. Здесь Россия использует все возможности для восстановления мира, а также поддержания должного уровня безопасности [Рыжов, Тоцкая, 2016, с. 86]. В свете этого особое значение имеет существование на Ближнем Востоке конфликтов, успехи в урегулировании которых, достигнутые при российском участии, ещё более увеличат авторитет нашей страны на международной арене.

Внимание авторов сфокусировано на конфликте между Государством Израиль и радикальной ливанской организацией «Хезболла» («Партия Аллаха»). Его важнейшим эпизодом стали события 2006 г. - Вторая ливанская война. После неё Тель-Авив сосредоточил свои усилия на борьбе с действующими на палестинских территориях группировками, а именно на юге, что нашло выражение в проведении крупномасштабных операций «Литой свинец», «Облачный столп» и «Нерушимая скала» в секторе Газа в период 2008-2014 гг. Кроме них среди действий израильской стороны на палестинском направлении ввиду места проведения, а также итогов выделяется имевшая место в 2014 г. масштабная операция «Возвращайтесь, братья» на Западном берегу реки Иордан (подробнее см.: [Морозов, Ермаков, 2016]).

Уже после этого - зимой 2018-2019 гг. - открылась новая страница в противостоянии между Израилем и «Партией Аллаха».

Речь идёт об операции вооружённых сил Израиля (Армия обороны Израиля или АОИ или ЦАХАЛ) на северной границе своей страны. Хотя по масштабу эти события нельзя поставить в один ряд со Второй ливанской войной, их значение для продолжающегося конфликта между Израилем и «Хезболлой» очень велико. Как и предшествовавшие им военные действия в 2006 году, они наглядно продемонстрировали, насколько опасным противником для Тель-Авива являются действующие на территории Ливана боевики. Кроме того, не беря в расчёт операцию АОИ на ливано-израильской границе и связанные с ней события, невозможно дать объективную оценку текущей политики руководства Израиля в сфере безопасности, которая выстраивается в том числе с учётом возрастающего влияния Российской Федерации на Ближнем Востоке. 


\section{Действия Израиля}

4 декабря 2018 г. АОИ начала операцию «Северный щит» по нейтрализации ведущих на территорию Израиля тоннелей «Хезболлы». При этом было заявлено, что операция будет осуществляться только на израильской территории ${ }^{63}$. В результате была уничтожена сеть тоннелей, созданная для захвата населённых пунктов в Галилее, которую радикалы планировали использовать в новом конфликте с Израилем [Rasgon, Staff, 2019]. Всего было нейтрализовано 6 таких сооружений, в том числе в районе города Метула ${ }^{64}$, который из-за своего расположения особенно уязвим для атак со стороны Ливана. О завершении работ по уничтожению последнего тоннеля «Хезболлы», который вёл на территорию Израиля, пресс-служба ЦАХАЛ сообщила 30 мая 2019 г. ${ }^{65}$

Среди нейтрализованных израильтянами объектов «Партии Аллаха» особо выделяется тоннель, уходивший под землю на глубину 80 м - а это примерно 22 этажа - и имевший протяжённость около 1 км [Staff, Ari Gross, 2019]. Как отметили израильские военные, данный тоннель «Хезболлы» представлял собой намного более серьёзный инженерный проект, нежели тоннели ХАМАС. Его обнаружение не должно было являться неожиданностью для израильской стороны, так как до этого в районе границы с Израилем уже был уничтожен тоннель, который также можно отнести к суперсооружениям «Партии Аллаха» ${ }^{66}$. Строительство этих объектов является одним из свидетельств того, насколько серьёзную военную угрозу «Хезболла» представляет для Израиля.

Успешное завершение операции «Северный щит» имело большое значение не только для противостояния между Израилем и «Хезболлой». Так, снижение возможностей «Партии Аллаха» наносить удары по израильскому тылу - лишь одно из последствий операции. Ввиду существующего в Израиле дисбаланса в защите юга и севера страны не в пользу последнего (подробнее см.: [Ермаков, Рыжов, 2018, с. 59]) нейтрализация угрозы атак из-под земли со стороны ливанских радикалов явилась значительным вкладом в повышение стойкости тыла, угроза которому также исходит от палестинских боевиков. Здесь нужно отметить, что «Хезболла» и действующие на территории сектора Газа боевики обладают сходными средствами вооружённой борьбы против Израиля. Среди них наиболее опасными для него являются те, которые позволяют оказывать давление на израильский тыл, что обусловлено чувствительностью последнего к такому воздействию. Подобными средствами как раз являются тоннели, по которым боевики могут проникать на территорию Израиля, и ракетное вооружение. Ввиду этого одним из приоритетов для Тель-Авива в конфликте с ливанскими и палестинскими радикалами является реализация мер, направленных на нейтрализацию угроз израильскому тылу. Одной из них стала операция «Северный щит». При этом ввиду характера и масштаба угроз израильтяне вынуждены заниматься осуществлением и других подобных мер.

Начнём с того, что в 2019 г. продолжалось строительство подземного заграждения на границе с сектором Газа, предназначенного для защиты израильской территории от трансграничных тоннелей. По данным министерства обороны Израиля, на июль 2019 г. было завершено строительство 40 км этой подземной преграды из запланированных более 60 км ${ }^{67}$. Ещё раньше - в феврале 2019 г. - премьер-министр страны Биньямин Нетаньяху

${ }^{63}$ Об изменениях в военно-политической обстановке на Ближнем Востоке и в Северной Африке (3-9 декабря 2018 года). 2018. URL: http://www.iimes.ru/?p=50924 (дата обращения: 02.10.2019).

${ }^{64}$ Премия за вклад в безопасность Израиля будет вручена причастным к раскрытию туннелей «Хезбаллы». 2019. URL: http://newsru.co.il/israel/04jun2019/hizb302.html (дата обращения: 04.10.2019).

${ }^{65}$ ЦАХАЛ «запечатал» мегатуннель «Хезбаллы», уходивший под землю на 22 этажа. ВИДЕО. 2019. URL: http://newsru.co.il/israel/30may2019/idf_tunnel_005.html (дата обращения: 27.09.2019).

${ }^{66}$ ЦАХАЛ уничтожил двухкилометровый туннель боевиков «Хизбаллы». 2006. URL: http://newsru.co.il/mideast/27aug2006/bun_piz.html (дата обращения: 27.09.2019).

${ }^{67}$ Построены 40 км подземной преграды на границе с $\quad$ Газой. $2019 . \quad$ URL: http://newsru.co.il/israel/16jul2019/gaza310.html (дата обращения: 22.09.2019). 
сообщил о начале возведения бетонной стены вокруг сектора Газа с целью предотвращения проникновения наземным путём на израильскую территорию ${ }^{68}$.

Большое внимание израильтяне уделяют повышению стойкости тыла к ракетным обстрелам со стороны радикалов. В 2019 г. сообщалось, что ЦАХАЛ принял решение реорганизовать систему предупреждения о ракетных обстрелах - число районов предупреждения должно значительно возрасти, и предупреждение о ракетном обстреле станет получать каждый населённый пункт. При этом 10 крупных городов разделят на отдельные зоны: так, при ракетном обстреле северной части Тель-Авива сирена не будет включаться в его восточных или южных районах. По словам израильских военных, данные меры помогут предотвратить ситуацию, когда в убежищах находятся сотни тысяч человек ${ }^{69}$. Если такого результата удастся достичь, то по своей значимости реорганизация системы предупреждения о ракетных обстрелах может быть поставлена в один ряд с развёртыванием предназначенных для перехвата ракет систем противоракетной обороны - уже успевшего зарекомендовать себя «Железного купола», а также «Пращи Давида».

Говоря об этих усилиях, стоит отметить их актуальность и своевременность - ввиду нейтрализации Израилем подземной инфраструктуры боевиков на своих южной и северной границах последние будут вынуждены интенсифицировать развитие имеющегося у них ракетного вооружения. Однако среди противостоящих израильтянам мощных радикальных организаций - палестинских ХАМАС и «Исламского джихада», а также ливанской «Хезболлы» - в этом плане наибольшую угрозу для Тель-Авива представляет именно «Партия Аллаха», обладающая, по сравнению с остальными, самыми широкими возможностями реализации своих военных приготовлений. Такое положение дел во многом обусловлено тем, что необходимая для модернизации ракетного арсенала инфраструктура ХАМАС и «Исламского джихада» в основном сосредоточена в блокадном секторе Газа. Сохранение, а также расширение радикальной ливанской организацией имеющихся у неё возможностей для подготовки к новому вооружённому конфликту - залог того, что она продолжит оставаться одним из наиболее опасных противников Израиля. Здесь уместно заметить, что Биньямин Нетаньяху отметил такие военные инструменты «Хезболлы», как тоннели и не обладающие большой точностью ракеты. «Но шиитская террористическая организация мечтает о высокоточном оружии, и это радикально меняет баланс сил», - сказал при этом израильский лидер ${ }^{70}$.

Следует также указать на то, что ранее вооружённые силы Израиля были недостаточно готовы к борьбе с «тоннельной угрозой» со стороны радикалов (подробнее см.: [Ермаков, Морозов, 2017, с. 20]). Поэтому операцию «Северный щит» можно рассматривать как демонстрацию Тель-Авивом своих возросших возможностей в данной сфере противоборства с ливанскими и палестинскими боевиками. В пользу такой оценки операции АОИ свидетельствует и проведённая к ней подготовка. Сообщалось, что в ходе неё была развёрнута лаборатория по обнаружению тоннелей, при создании которой учитывался опыт, полученный на границе с палестинским анклавом ${ }^{71}$. Так, Израиль может указать на достижение оперативно-разведывательно-технологического прогресса в отношении угрозы туннелей, прорытых «Хезболлой» на его суверенной территории, на северной границе с Ливаном. Израиль разоблачил и уничтожил туннели, не обостряя ситуацию, но в то же время усиливая в определенной степени свое долгосрочное сдерживание в отношении

${ }^{68}$ Об изменениях в военно-политической обстановке на Ближнем Востоке и в Северной Африке (28 января - 3 февраля 2019 года). 2019. URL: http://www.iimes.ru/?p=53122 (дата обращения: 23.09.2019).

${ }^{69}$ ЦАХАЛ меняет систему предупреждения о ракетных обстрелах израильской территории. 2019. URL: http://newsru.co.il/israel/12jun2019/azakot_707.html (дата обращения: 22.09.2019).

${ }^{70}$ В Иерусалиме состоялась церемония награждения отличившихся агентов «Мосада». 2018. URL: http://newsru.co.il/israel/06dec2018/mosad_0015.html (дата обращения: 26.09.2019).

${ }^{71}$ ЦАХАЛ опубликовал «голос» наступательного туннеля «Хизбаллы». 2018. URL: http://newsru.co.il/israel/10dec2018/idf_voix_006.html (дата обращения: 26.09.2019). 
«Хезболлы» ${ }^{72}$. Это же обстоятельство позволяет считать операцию «Северный щит» продолжением действий по борьбе с «тоннельной угрозой», предпринятых израильтянами на границе с Газой в 2014 г. в ходе крупномасштабной операции «Нерушимая скала» (подробнее см.: [Бородина, Ермаков, Рыжов, 2014]), а также в последующий период.

Можно констатировать, что взаимосвязанные шаги израильской стороны, о которых говорилось выше (операция «Северный щит» на границе с Ливаном, возведение защитных сооружений вдоль границы с сектором Газа, а также реорганизация системы предупреждения о ракетных обстрелах), направлены на то, чтобы не позволить ливанским и палестинским боевикам значительно усилить свои позиции в продолжающемся конфликте. Однако израильтяне обладают ограниченными возможностями для сдерживания роста военной угрозы со стороны противостоящих им радикальных организаций, которые имеют поддержку государственных акторов.

Налицо нехватка у Тель-Авива значительного числа необходимых ресурсов для эффективного противодействия «Хезболле» в условиях продолжающегося затяжного конфликта, арена которого простирается далеко за пределы Ливана. К тому же израильтяне вынуждены задействовать ресурсы в противоборстве с палестинскими радикалами, и меры, осуществляемые ими на границе с Газой после операции «Нерушимая скала», являются одним из проявлений этого. Важно заметить, что сегодняшнее состояние конфликта на палестинской арене для израильской стороны определяет необходимость реализации, в дополнение к существующим, новых мер в сфере защиты тыла. Это, в свою очередь, предполагает ещё большие расходы. Ограниченность ресурсов, среди прочих факторов, обуславливает для Израиля необходимость на текущий момент воздерживаться от эскалации противостояния в секторе Газа.

В сложившихся обстоятельствах для Тель-Авива возрастает ценность дальнейшего развития военно-политических контактов с наиболее влиятельными игроками на Ближнем Востоке из числа великих держав - США и Россией. И если такое сотрудничество между Израилем и Соединёнными Штатами традиционно находится на достаточно высоком уровне, то интенсификация российско-израильского взаимодействия по военнополитической линии сегодня стала новой реальностью ближневосточного региона ${ }^{73}$. При этом израильское направление внешней политики имеет большое значение для Москвы в рамках реализации её ближневосточного курса, что создаёт дополнительные «точки соприкосновения» в процессе развития диалога между двумя сторонами.

\section{Роль Российской Федерации}

В столь непростой для израильского руководства военно-политической ситуации фактор присутствия России на Ближнем Востоке всё более возрастает. Дипломатические и военные позиции РФ на линиях противостояния Израиля и негосударственных вооружённых формирований в лице «Хезболлы» и палестинских радикалов контрастируют с возможностями не только стран Запада, но и государств самого ближневосточного региона. Ведь Москва имеет хорошие отношения и развивает диалог со всеми участниками противоборства и потому предпринимает определенные усилия к умиротворению, которые сегодня особенно важны.

Как отметил начальник генерального штаба ЦАХАЛ генерал-лейтенант Авив Кохави, «на севере и на юге сложилась напряженная обстановка, которая может в любой момент скатиться к войне, несмотря на то, что наши враги на текущий момент в ней не заин-

\footnotetext{
${ }^{72}$ Operation Northern $\quad$ Shield: Interim $\quad$ Assessment. $2019 . \quad$ URL: https://www.inss.org.il/publication/operation-northern-shield-interim-assessment/ (accessed 23.09.2019).

${ }^{73}$ Russia's return to the Middle East Building sandcastles? July 2018. / ed. by Nicu Popescu and Stanislav Secrieru // ISSUE / EU Institute for Security Studies. № 146. 123 p.
} 
тересованы». При этом главной стратегической угрозой для Израиля объявляется ситуация на севере - в Сирии и Ливане ${ }^{74}$, то есть на территориях, где российское влияние достаточно высоко и наблюдаются предпосылки для его дальнейшего роста.

Таким образом, для обеспечения безопасности Израиля действия России крайне важны, что делает её одним из ключевых игроков на израильском треке ближневосточной политики [Rumer, 2019]. Поэтому следует ожидать выхода контактов в военнополитической сфере между Израилем и РФ на новый уровень. Однако многое будет зависеть от позиции нового израильского правительства. Здесь наиболее вероятным сценарием видится сохранение Тель-Авивом существующего курса в отношениях с Москвой.

Между тем действия России на Ближнем Востоке можно условно разделить на две приоритетные сферы. Дипломатическую линию продвигает МИД РФ под руководством Сергея Лаврова, и цель внешнеполитического ведомства - свести к минимуму политические претензии сторон друг к другу, принять обязательства не нарушать прекращение огня, не поддаваться на различные провокации. Требования Израиля понять можно, однако выполнить не так просто. Израильские дипломаты утверждают: принципиальный шаг к стабильности - это полная эвакуация иранских сил из Сирии, а также прекращение поддержки Ираном «Хезболлы» и других организаций, признанных в Израиле террористическими ${ }^{75}$.

Тель-Авив полагает, что Москва способна оказать давление на «Хезболлу» и ХАМАС. Последний остаётся господствующей в секторе Газа силой, и от него, в числе прочих организаций, зависит упомянутый выше «Исламский джихад». Аргументы израильской стороны следующие: оба движения не входят в список террористических организаций в РФ; российской стороной установлен механизм постоянных консультаций с этими структурами по дипломатической линии; «Партия Аллаха» и Воздушно-космические силы (BKC) России защищают режим Башара Асада на территории Сирии. Также Москва придерживается позиции, что после полной победы над террористами для установления политической стабильности в регионе все иностранные формирования должны покинуть сирийскую территорию. Здесь интересы РФ и Израиля совпадают.

Военную линию умиротворения поддерживает Министерство обороны РФ, задача которого состоит в том, чтобы вести широкий информационный обмен с представителями ЦАХАЛ. Полагаем, что ведомство Сергея Шойгу стремится создать гибкую систему взаимодействия с командованием АОИ, которая включала бы в себя «правила игры» и на общем для обеих сторон сирийском театре боевых действий.

На переговорах представителей генералитета двух стран обсуждаются вопросы улучшения координации действий израильских и российских военных в Сирии, по отношению к которой ЦАХАЛ использует термин «северная арена», а также функционирования прямого канала связи российской авиабазы «Хмеймим» и командного центра военновоздушных сил (BBC) Израиля для предотвращения опасных инцидентов, несущих угрозу жизни военнослужащим двух стран. Израильская сторона подчёркивает, что АОИ продолжит действовать против иранских сил и поставок вооружения «Хезболле» в Сирии 76 , что заставляет российских военных корректировать свои оперативные планы.

Как дипломатическое, так и военное направление взаимодействия курирует лично Президент России Владимир Путин, который наладил регулярный обмен мнениями и механизм выработки оперативных решений со своим израильским коллегой Биньямином

${ }^{74}$ Начгенштаба ЦАХАЛа: «Ситуация может в любой момент скатиться к войне на севере и на юге». 2019. URL: http://newsru.co.il/israel/24oct2019/kohavi310.html (дата обращения: 29.10.2019).

${ }^{75}$ Кац и Лавров обсудили в Нью-Йорке актуальные вопросы израильско-российских отношений. 2019. URL: http://newsru.co.il/world/26sep2019/katz_lavrov.html (дата обращения: 30.10.2019).

${ }^{76}$ В Москве прошли переговоры представителей армий Израиля и России. 2018. URL: http://newsru.co.il/israel/12dec2018/tzahal_ru_110.html (дата обращения: 30.10.2019). 
Нетаньяху ${ }^{77}$. О значимости таких контактов лидеров двух стран наглядно свидетельствуют слова последнего. «У меня только что был важный разговор с президентом России Владимиром Путиным. Несколько недель назад я встречался с ним и обсуждал важные для безопасности Израиля вопросы. Сегодняшняя беседа также важна для безопасности Израиля. Перед нами стоят непростые задачи, но мы их решаем, в том числе благодаря сотрудничеству и важной координации с Россией. Это критически важно для нас, и мы продолжим так действовать», - заявил он в октябре 2019 г. ${ }^{78}$

$* * * *$

Подводя итог всему вышесказанному, можно справедливо утверждать, что операция «Северный щит» вкупе с инфраструктурными проектами в сфере защиты тыла играет важнейшую роль в контексте реализации премьер-министром Биньямином Нетаньяху политики безопасности Государства Израиль (подробнее см.: [Корнилов, 2019]).

Данная операция наряду с другими событиями в регионе проявила две ключевые тенденции развития конфликта между Тель-Авивом и «Хезболлой», которые необходимо учитывать при выработке и реализации внешнеполитического курса Российской Федерации на Ближнем Востоке. Первая тенденция заключается в том, что территория Ливана остаётся главной локацией в конфликте между израильтянами и «Партией Аллаха». Важно заметить, что такое положение дел будет сохраняться и в обозримой перспективе, чему способствуют действия Израиля на территории Сирии, которые ослабляют позиции «Хезболлы» во всём ближневосточном регионе. Вторая тенденция состоит в том, что ТельАвив наращивает усилия в противостоянии с «Партией Аллаха», что обусловлено уровнем военной угрозы для Израиля со стороны последней, а также стремлением израильского руководства не допустить его дальнейший рост. Здесь важнейшим обстоятельством является то, что эти действия израильской стороны предпринимаются в условиях продолжающегося конфликта на палестинских территориях, в том числе в секторе Газа, где вооружённое противостояние может вспыхнуть буквально в любой момент. Это, среди прочих факторов, повышает заинтересованность израильтян в нормализации обстановки вокруг палестинского анклава. Однако, как показало развитие палестино-израильского конфликта, без расширения международного участия такая разрядка не может быть достигнута ни сегодня, ни в обозримом будущем. При этом налицо недостаточное участие в данном процессе статусных акторов международных отношений.

В свете этого прослеживается ряд актуальных направлений выработки и реализации внешнеполитического курса России в ближневосточном регионе. Первое из них увеличение активности на ливанском треке ближневосточной политики с акцентом на недопущение эскалации конфликта между Тель-Авивом и «Хезболлой». Важно заметить, что этому способствует взаимосвязь происходящего в Ливане и Сирии, предоставляющая российской стороне рычаги для оказания воздействия на сложившуюся обстановку ${ }^{79}$. Второе - это расширение участия в урегулировании палестино-израильского конфликта с уделением особого внимания деэскалации противостояния в секторе Газа. Здесь одним из благоприятствующих факторов является обладание Россией статуса великой державы. Из данного направления вытекает третье - дальнейшее наращивание сотрудничества с Египтом, без деятельного участия которого нормализация обстановки на территории палестинского анклава просто не представляется возможной, одним из доказательств чего является ключевая роль Каира в прекращении вооружённого противоборства в Газе. Учитывая вы-

77 Телефонный разговор с Премьер-министром Израиля Биньямином Нетаньяху. 2019. URL: http://kremlin.ru/events/president/news/59357 (дата обращения: 30.10.2019).

${ }^{78}$ Состоялся телефонный разговор Биньямина Нетаниягу и Владимира Путина.2019. URL: http://newsru.co.il/israel/07oct2019/putin_702.html (дата обращения: 30.10.2019).

${ }^{79}$ Russia's return to the Middle East Building sandcastles? July 2018 / ed. by Nicu Popescu and Stanislav Secrieru // ISSUE / EU Institute for Security Studies. № 146. 123 p. 
шесказанное, а также стремление правительства Нетаньяху - Ганца решить вопрос о статусе части территорий Западного берега реки Иордан, реалистичной представляется перспектива запуска Москвой новой площадки переговорного процесса Израиля и Палестины. Открытый в подобном Астанинскому формате, процесс переговоров способен, по крайней мере, начать диалог непримиримых сторон - диалог, столь важный на фоне кровавой истории палестино-израильского конфликта.

\section{Список литературы}

1. Бородина М.Ю., Ермаков А.А., Рыжов И.В. 2014. Летняя война 2014 года в Газе. Новая страница палестино-израильского конфликта. Азия и Африка сегодня, № 12 (689): 16-20.

2. Ермаков А.А., Морозов В.М. 2017. Эхо летней войны в секторе Газа. Азия и Африка сегодня, № 10 (723): 18-21.

3. Ермаков А.А., Рыжов И.В. 2018. Развитие противостояния Государства Израиль и радикалов сектора Газа: «доктрина Либермана». Вестник Брянского государственного университета, № 3 (37): 57-63.

4. Корнилов А.А. 2019. Стратегические альянсы и региональные союзы во внешнеполитических идеях премьер-министров Израиля Давида Бен-Гуриона и Биньямина Нетаньяху. Регион им ир, том Х, № 1: 23-27.

5. Морозов В.М., Ермаков А.А. 2016. Операция «Возвращайтесь, братья» в контексте палестино-израильского противостояния. Вестник МГИМО-Университета, № 4 (49): 131-136.

6. Рыжов И.В., Тоцкая Е.П. 2016. Анализ политики России на Ближнем Востоке в 2000-2015 гг. в работах российских исследователей. Вестник Нижегородского университета им. Н.И. Лобачевского, № 4: 82-90.

7. Rasgon A., Staff T. January 26, 2019. Nasrallah: Israeli tunnel op hasn’t curbed «10 percent» of Galilee invasion plan / Adam Rasgon, Toi Staff // The Times of Israel. URL: https://www.timesofisrael.com/idf-reveals-longest-most-significant-hezbollah-tunnel-yet-on-northernborder/.

8. Rumer E. October 2019. Russia in the Middle East: Jack of All Trades, Master of None / Eugene Rumer // Carnegie Endowment For International Peace, The Return of Global Russia. URL: https://carnegieendowment.org/files/WP-Rumer-MiddleEast.pdf.

9. Staff T., Ari Gross J. May 30, 2019. IDF reveals «longest, most significant» Hezbollah tunnel on northern border / Toi Staff, Judah Ari Gross // The Times of Israel. URL: https://www.timesofisrael.com/idf-reveals-longest-most-significant-hezbollah-tunnel-yet-on-northernborder/.

\section{References}

1. Borodina M.Yu., Ermakov A.A., Ryzhov I.V. 2014. Letnyaya voina 2014 goda v Gaze. Novaya stranitsa palestino-izrail'skogo konflikta [Summer war 2014 in Gaza: the new page of the Palestinian - Israeli conflict]. Asia and Africa today, no. 12 (689): 16-20.

2. Ermakov A.A., Morozov V.M. 2017. Ekho letnei voiny v sektore Gaza [Echo of summer war in the Gaza Strip]. Asia and Africa today, no. 10 (723): 18-21.

3. Ermakov A.A., Ryzhov I.V. 2018. Razvitie protivostoyaniya Gosudarstva Izrail' i radikalov sektora Gaza: «doktrina Libermana» [Evolution of the confrontation between Israel and the radicals of the Gaza Strip: Lieberman's military doctrine]. The Bryansk State University Herald, vol. 3, no. 37: 57-63.

4. Kornilov A.A. 2019. Strategicheskie al'yansy i regional'nye soyuzy vo vneshnepoliticheskikh ideyakh prem'er-ministrov Izrailya Davida Ben-Guriona i Bin'yamina Netan'yakhu [Strategic alliances and regional alliances in foreign policy ideas of Israeli Prime Ministers David Ben-Gurion and Benjamin Netanyahu]. Region and the World, vol. X, no. 1: 23-27.

5. Morozov V.M., Ermakov A.A. 2016. Operatsiya «Vozvrashchaites', brat'ya» v kontekste palestino-izrail'skogo protivostoyaniya [Operation «Brother's Keeper» in Context of the Palestinian Israeli Standoff]. MGIMO Review of International Relations, no. 4 (49): 131-136.

6. Ryzhov I.V., Totskaya E.P. 2016. Analiz politiki Rossii na BlizhnemVostoke v 2000-2015 gg. [The analysis of Russian policy in the Middle East in the studies of Russian researchers 
in 2000-2015]. V rabotakh rossiiskikh issledovatelei. Vestnik of Lobachevsky State University of Nizhnii Novgorod, no. 4: 82-90.

7. Rasgon A., Staff T. January 26, 2019. Nasrallah: Israeli tunnel op hasn't curbed «10 percent» of Galilee invasion plan / Adam Rasgon, Toi Staff // The Times of Israel. URL: https://www.timesofisrael.com/idf-reveals-longest-most-significant-hezbollah-tunnel-yet-on-northernborder/.

8. Rumer E. October 2019. Russia in the Middle East: Jack of All Trades, Master of None / Eugene Rumer // Carnegie Endowment For International Peace, The Return of Global Russia. URL: https://carnegieendowment.org/files/WP-Rumer-MiddleEast.pdf.

9. Staff T., Ari Gross J. May 30, 2019. IDF reveals «longest, most significant» Hezbollah tunnel on northern border / Toi Staff, Judah Ari Gross // The Times of Israel. URL: https://www.timesofisrael.com/idf-reveals-longest-most-significant-hezbollah-tunnel-yet-on-northernborder/.

\section{ИНФОРМАЦИЯ ОБ АВТОРАХ}

Ермаков Андрей Александрович, кандидат исторических наук, г. Нижний Новгород, Россия

Корнилов Александр Алексеевич, доктор исторических наук, профессор, заведующий кафедрой зарубежного регионоведения и локальной истории, Национальный исследовательский государственный им. Н.И. Лобачевского, международных отношений и мировой истории, г. Нижний Новгород, Россия

Рыжов Игорь Валерьевич, доктор исторических наук, доцент, заведующий кафедрой истории и политики России, Национальный исследовательский Нижегородский государственный университет им. Н.И. Лобачевского, Институт международных отношений и мировой истории г. Нижний Новгород, Россия

\section{INFORMATION ABOUT THE AUTHORS}

Andrey A. Ermakov, Ph.D. (World History), Nizhny Novgorod, Russia

Alexander A. Kornilov, Dr. of Sci. (World History), Professor, Head of the Chair of Foreign Regions Studies and Local History, Institute of International Relations and World History, National Research Lobachevsky State University of Nizhny Novgorod, Nizhny Novgorod, Russia

Igor V. Ryzhov, Dr. of Sci. (World History), Associate Professor, Head of the Chair of Russian History and Politics, Institute of International Relations and World History, National Research Lobachevsky State University of Nizhny Novgorod, Nizhny Novgorod, Russia 